\title{
Dual-fuzzy MPPT in photovoltaic-DC analysis for dual-load operation with SEPIC converter
}

\begin{abstract}
In this paper, dual-fuzzy based maximum power point tracking (MPPT) is proposed for standalone photovoltaic (PV) system, working for dual-load operation. The proposed MPPT consists of two different fuzzy logic controllers (FLCs) to support operation of single ended primary-inductor converter (SEPIC) in buck and boost conditions, by depending on irradiance conditions. To realize dual-operation of SEPIC, dual-load approach has been applied by selecting suitable load resistance, which could achieve maximum power point (MPP) with specific irradiance and duty cycle. Then, relationship between irradiance, load resistance and duty cycle has been discussed in details. The dual-fuzzy based MPPT together with PV module of Kyocera KD210GH-2PU connected to SEPIC was simulated in MATLAB-Simulink, and further the laboratory prototype with TMS320F28335 eZdsp board was implemented. Each load was connected to direct current (DC) supply to ensure continuity of the supply to both loads. Both simulation and experimental results and comparison analysis (with $\mathrm{P} \& \mathrm{O}$ ) have been presented. From the results and analysis, dualfuzzy based MPPT with dual loads shows that by switching from PV to DC, there is no change in output voltage, but during the switching from DC to PV, there are significant changes that can be noticed according to the irradiances.
\end{abstract}

Keyword: Dual loads; Fuzzy logic; MPPT; Photovoltaic SEPIC dc-dc converter 